\title{
Maxillary sinus surgery in maxillary sinusitis with cystic fibrosis
}

\author{
Alper Nabi Erkan
}

Received: 19 January 2013/Accepted: 15 February 2013/Published online: 2 March 2013

(C) Springer-Verlag Berlin Heidelberg 2013

To the Editor,

We read the article which was written by Vital et al. [1] in your journal. We agree with their opinion. In cystic fibrosis patients with chronic sinusitis, extensive sinus surgery and daily nasal care are necessary. But if there is maxillary sinusitis with cystic fibrosis, wide middle meatal antrostomy will not be enough. In this occasion inferior meatal antrostomy must be performed, because nasal secretion accumulates in the inferior part of the maxillary sinus.
Conflict of interest The author declares no financial relationship with the organization that sponsored the research.

\section{Reference}

1. Vital D, Hofer M, Boehler A, Holzmann D (2013) Posttransplant sinus surgery in lung transplant recipients with cystic fibrosis: a single institutional experience. Eur Arch Otorhinolaryngol 270(1):135-139
A. N. Erkan $(\square)$

Department of Otorhinolaryngology, Baskent University,

Baraj Yolu 1. Durak, 01110 Seyhan-Adana, Turkey

e-mail: alpernabierkan@yahoo.com 